\title{
Chronic amyloid $\beta$ oligomer infusion evokes sustained inflammation and microglial changes in the rat hippocampus via NLRP3
}

Csaba Fekete ${ }^{1,2}$, Csaba Vastagh $^{1}$, Ádám Dénes ${ }^{3}$, Erik Hrabovszky ${ }^{1}$, Gábor Nyiri ${ }^{4}$, Imre Kalló ${ }^{1,5}$, Zsolt Liposits ${ }^{1,5}$ and Miklós Sárvári ${ }^{1 *}$

${ }^{1}$ Department of Endocrine Neurobiology, Institute of Experimental Medicine, Hungarian Academy of Sciences, Budapest, Hungary; ${ }^{2}$ Department of Medicine, Division of Endocrinology, Diabetes and Metabolism, Tupper Research Institute, Tufts Medical Center, Boston, MA 02111, USA; 3"Momentum" Laboratory of Neuroimmunology, Institute of Experimental Medicine, Hungarian Academy of Sciences, Budapest, Hungary; ${ }^{4}$ Laboratory of Cerebral Cortex Research, Institute of Experimental Medicine, Hungarian Academy of Sciences, Budapest, Hungary; ${ }^{5}$ Faculty of Information Technology and Bionics, Pázmány Péter Catholic University, Budapest, Hungary

Statement: The authors have no conflict of interest to declare.

* Corresponding author

Miklós Sárvári, PhD

Department of Endocrine Neurobiology

Institute of Experimental Medicine

Hungarian Academy of Sciences

Szigony u 43., H-1083 Budapest, Hungary

E-mail: sarvari.miklos@koki.mta.hu

Telephone: $+36(1) 2109400$

Fax: +36(1)2109944 


\begin{abstract}
Abbreviations
$\mathrm{A} \beta$ : amyloid beta; $\mathrm{A} \beta \mathrm{O}: \mathrm{A} \beta_{1-42}$ oligomers; $\mathrm{AD}$ : Alzheimer's disease; CSF: cerebrospinal fluid; icv.: intracerebroventricular; IL-10: interleukin-10; mRNA: messenger RNA; MWM: Morris water maze; NLRP3: Nod-like receptor family, pyrin domain-containing 3
\end{abstract}




\begin{abstract}
Microglia are instrumental for recognition and elimination of amyloid $\beta_{1-42}$ oligomers $(A \beta O)$, but the long-term consequences of A $\beta \mathrm{O}$-induced inflammatory changes in the brain are unclear. Here, we explored microglial responses and transciptome-level inflammatory signatures in the rat hippocampus after chronic $\mathrm{A} \beta \mathrm{O}$ challenge. Middle-aged Long Evans rats received intracerebroventricular infusion of $\mathrm{A} \beta \mathrm{O}$ or vehicle for 4 weeks, followed by treatment with artificial CSF or MCC950 for the subsequent 4 weeks. A $\beta O$ infusion evoked a sustained inflammatory response including activation of $\mathrm{NF}-\kappa \mathrm{B}$, triggered microglia activation and increased the expression of pattern recognition and phagocytic receptors. $A \beta_{1-42}$ plaques were not detectable likely due to microglial elimination of infused oligomers. In addition, we found upregulation of neuronal inhibitory ligands and their cognate microglial receptors, whilst downregulation of Esrl and Scnla, encoding estrogen receptor alpha and voltage-gated sodium-channel $\mathrm{Na}(\mathrm{v}) 1.1$, respectively, was observed. These changes were associated with impaired hippocampus-dependent spatial memory and resembled early neurological changes seen in Alzheimer's disease. To investigate the role of inflammatory actions in memory deterioration, we performed MCC950 infusion, which specifically blocks the NLRP3 inflammasome. MCC950 attenuated AßO-evoked microglia reactivity, restored expression of neuronal inhibitory ligands, reversed downregulation of $\mathrm{ER} \alpha$ and $\mathrm{Na}(\mathrm{v}) 1.1$, and abolished memory impairments. Furthermore, MCC950 abrogated AßO-invoked reduction of serum IL10. These findings provide evidence that in response to $\mathrm{A} \beta \mathrm{O}$ infusion microglia change their phenotype, but the resulting inflammatory changes are sustained for at least one month after the end of $\mathrm{A} \beta \mathrm{O}$ challenge. Lasting NLRP3-driven inflammatory alterations and altered hippocampal gene expression contribute to spatial memory decline.
\end{abstract}

\title{
Keywords
}

amyloid $\beta_{1-42}$ oligomer, hippocampus, microglia, NLRP3 inflammasome, estrogen receptors, spatial memory 


\section{Introduction}

Microglia constantly survey the brain parenchyma (Nimmerjahn, Kirchhoff, \& Helmchen, 2005) and react promptly to disturbances to maintain homeostasis (Hanisch \& Kettenmann, 2007). Microglia are equipped with receptors to monitor neurotransmission, neuronal damage, and to recognize any foreign or harmful substances (Lucin \& Wyss-Coray, 2009). Microglial cells are instrumental in the recognition and elimination of amyloid beta $(A \beta)$. Cell surface receptors including scavenger receptors (El Khoury et al., 1996), CD14, TLR2 and TLR4 (Reed-Geaghan, Savage, Hise, \& Landreth, 2009) bind A $\beta$, resulting in activation of NF- $\mathrm{B}$ (Li, Long, He, Belshaw, \& Scott, 2015). Activation of NF- $\kappa B$ triggers transcription of a set of proinflammatory genes (Muruve et al., 2008) including IL1B and NLRP3. Thereafter, encounter of A $\beta$ lysosomal fragments and NLRP3 facilitates formation and activation of the NLRP3 inflammasome complex which promotes the release of IL-1 $\beta$ and IL-18, modulates eicosanoid synthesis, autophagy, metabolism and gene transcription (Rathinam \& Fitzgerald, 2016). Activation of the NLRP3 inflammasome has been demonstrated in Alzheimer's disease (AD), and suggested that it plays a causative role in disease pathogenesis (Halle et al., 2008; Heneka et al., 2015). Recent preclinical studies have supported this notion. Genetic ablation of Nlrp3 improves memory in APP/PS1 mice (Heneka et al., 2013), whilst pharmacological inhibition of the NLRP3 inflammasome reduces genotype-related microglia activation and enhances memory in transgenic mouse models (Daniels et al., 2016; Dempsey et al., 2016).

A $\beta$ peptides form soluble oligomers of various sizes, and aggregate into amyloid fibrils that gradually accumulate as insoluble senile plaques in the AD brain (Ahmed et al., 2010; Burdick et al., 1992; Halverson, Fraser, Kirschner, \& Lansbury, 1990; Kirschner et al., 1987; Kuo et al., 1996). The presence of activated microglia, many of which express IL-1 (Griffin et al., 1989), has been demonstrated at the plaques throughout the cerebral cortex (Itagaki, McGeer, Akiyama, Zhu, \& Selkoe, 1989; McGeer, Itagaki, Tago, \& McGeer, 1987). While A $\beta_{1-42}$ fibrils are unable to evoke a strong microglial response, soluble $A \beta_{1-42}$ oligomers $(A \beta O)$ activate microglia at the low nanomolar concentrations (Maezawa, Zimin, Wulff, \& Jin, 2011). Soluble $\mathrm{A} \beta \mathrm{O}$ has been implicated in the pathogenesis of AD (Bilousova et al., 2016; Lesne et al., 2006; Muller-Schiffmann et al., 2016; Shankar et al., 2008; Wang et al., 2017). The correlation between the degree of dementia in AD and the level of soluble A $\mathrm{OO}$ (Lue et al., 1999) supports this notion.

Infusion of $A \beta_{1-42}$ into the cerebral ventricles of young adult rats is an established approach to mimic the neurological phenotype of late-onset AD (Forny-Germano et al., 2014; Garcia-Matas 
et al., 2010; He et al., 2012; Lecanu, Greeson, \& Papadopoulos, 2006). Early studies suggest that $\mathrm{A} \beta$ fibrils alone are not effective to induce memory loss, but pro-oxidant agents potentiate the effect of $A \beta_{1-42}$, and the mixture of $A \beta_{1-42}$ and pro-oxidants causes microglia activation and memory disturbances (Lecanu et al., 2006). Recent studies have demonstrated that $A \beta O$ diffuse into the brain parenchyma (Forny-Germano et al., 2014) and evoke a more robust microglial response and memory loss than do $A \beta_{1-42}$ fibrils (He et al., 2012). Aging remains the major risk for the development of dementia. As age-related changes of the rat hippocampal transcriptome already occur at 6 month of age (Kadish et al., 2009), middle-aged rats have also been used in A $\beta$ infusion experiments (Frautschy et al., 2001; Frautschy, Yang, Calderon, \& Cole, 1996). However, it is currently unclear whether $\mathrm{A} \beta \mathrm{O}$ itself induces long-lasting inflammatory changes in the brain and memory deficits in an NLRP3-dependent manner.

In this study, we examined the impact of a 4-week $\mathrm{A} \beta \mathrm{O}$ infusion into the lateral cerebral ventricle of middle-aged Long Evans rats on microglia phenotype, inflammatory changes and transcriptomic fingerprints involved in neuron-microglia communication, estrogen signaling, inhibitory interneuron function and spatial memory. We also explored putative mechanisms that may link the microglial and inflammatory responses to $\mathrm{A} \beta \mathrm{O}$ infusion and spatial memory impairments. 


\section{Experimental procedures}

\section{Reagents}

$\mathrm{A} \beta_{1-42}$ peptide was purchased from Bachem (Bubendorf, Switzerland). Buthionine sulfoximine and iron sulfate heptahydrate were obtained from Santa Cruz Biotechnology (Santa Cruz, CA, USA) and Sigma (St. Louis, MO, USA), respectively. Rabbit polyclonal antiserum to Iba1 was ordered from Wako Chemicals GmbH, (Neuss, Germany). Monoclonal anti-A $\beta$ antibody was obtained from Abcam (Cambridge, UK). Artificial CSF and MCC950 (Coll et al., 2015) were purchased from Tocris (Bristol, UK) and Sigma, respectively.

\section{Preparation of A $\boldsymbol{\beta}_{1-42}$ oligomers}

$\mathrm{A} \beta_{1-42}$ peptide (Bachem, $\mathrm{H}-1368$ ) was dissolved in $10 \%$ (w/v) $\mathrm{NH}_{4} \mathrm{OH}$ (Ryan et al., 2013). Aliquots were prepared, freeze dried, and stored at $-20^{\circ} \mathrm{C}$. Prior to use, $1 \mathrm{mg}$ of $\mathrm{A} \beta_{1-42}$ was dissolved by adding $20 \mu \mathrm{l}$ of $60 \mathrm{mM} \mathrm{NaOH}$ and immediately diluted with $80 \mu \mathrm{l}$ water. Then, the alkaline solution was neutralized with $1.011 \mathrm{ml}$ of low salt buffer (10 mM HEPES pH7, 10 $\mathrm{mM} \mathrm{NaCl}$ ) to make a $0.2 \mathrm{mM} \mathrm{A} \beta_{1-42}$ solution. The solution was incubated for 4 hours on ice to promote oligomer formation (Ahmed et al., 2010). As pro-oxidant agents potentiate the effect of A $\beta$ (Garcia-Matas et al., 2010; Lecanu et al., 2006), we added $2.5 \mathrm{ml}$ low salt buffer containing $10 \mathrm{mg} \mathrm{FeSO}_{4} \cdot 7 \mathrm{H}_{2} \mathrm{O}$ and $96 \mathrm{mg}$ buthionine sulfoximine to the $\mathrm{A} \beta \mathrm{O}$ solution. The resulting solution consisted of $61.5 \mu \mathrm{M} \mathrm{A \beta O}, 10 \mathrm{mM} \mathrm{FeSO}_{4}$ and $0.12 \mathrm{M}$ buthionine sulfoximine. In parallel, the same solution without $A \beta_{1-42}$ was prepared and used for the treatment of control animals. Alzet 2004 minipumps (Durect, Cupertino, CA, USA), filled with these solutions, were incubated at room temperature for 16 hours in saline before use.

\section{Experimental animals}

Young male Long Evans rats were obtained from Charles River Laboratories (Calco, Italy). Animals were housed in the animal care facility of Institute of Experimental Medicine for the subsequent months. Eight month old rats were used in the study. APP ${ }^{\text {NL-F/NL-F }}$ mice were generated by Takaomi Saido's laboratory (Nilsson, Saito, \& Saido, 2014; Saito et al., 2014). For generation of the transgenic animal, the targeting vector was the mouse APP gene which included the Swedish and the Iberian human APP mutations (Mullan et al., 1992). The A $\beta$ sequence within the mouse APP was humanized. These mice have normal levels of full length APP, but show increased $A \beta_{1-42}: A \beta_{1-40}$ ratio characteristic for AD pathology (Hardy, 1997). Animals were kept under normal conditions, with 12/12 hour light cycles, food and water was available ad libitum. Unlike in any other existing AD mouse models, the APP ${ }^{\text {NL-F/NL-F }}$ mice reproduce human $\mathrm{AD}$ pathology with the highest fidelity. All studies were carried out with 
permission from the Animal Welfare Committee of Institute of Experimental Medicine (Permission Number: A5769-01), and in accordance with the legal requirements of the European Community (Directive 2010/63/EU). Animal experimentation described was conducted in accord with accepted standards of animal care.

\section{Surgery and treatment}

Surgery was carried out under isoflurane anesthesia, and with buprenorphine pain relief. Stainless steel infusion guide cannula (22G, Plastics One, Roanoke, VA, USA) was implanted into the right lateral cerebral ventricle $(\mathrm{D}=5.3 \mathrm{~mm}, \mathrm{~L}=1.4 \mathrm{~mm}, \mathrm{AP}=0.8 \mathrm{~mm})$. Alzet $2004 \mathrm{mini}-$ pumps filled with either $0.2 \mathrm{ml}$ of pro-oxidant-containing $61.5 \mu \mathrm{M} \mathrm{A} \beta \mathrm{O}$ solution or vehicle, were connected to the cannula via PE50 tubing (Plastics One) and placed under the skin in the interscapular region. Pumps released $1.67 \mu \mathrm{g}$ A $\beta O$ daily for 4 weeks. Dosage was selected based on the work of Frautschy et al. (Frautschy et al., 2001). After A $\beta O$ infusion, minipumps were replaced with new ones filled with either $0.2 \mathrm{ml}$ of $0.167 \mu \mathrm{g} / \mathrm{ml}$ MCC950 in artificial CSF (aCSF), or $0.2 \mathrm{ml}$ of aCSF. Dose of MCC950 was calculated based on published data on $\mathrm{IC}_{50}$ for NLRP3 (Coll et al., 2015). Pumps released $1.0 \mu \mathrm{g}$ MCC950 daily for 4 weeks. Consecutive treatments generated four experimental groups including control group (vehicle $+\mathrm{aCSF}, \mathrm{n}=6$ ), drug control group (vehicle + DRUG, $n=3$ ), A $\beta O$ challenged group $(A \beta O+a C S F, n=6)$ and MCC950 treatment group (A $\beta O+D R U G, n=8)$ were examined.

\section{Morris water-maze task}

On the fourth week of the second treatment, we started to perform Morris water maze (MWM). We tested spatial acquisition for 4 days, reversal on the next day and spatial learning for 2 days. The maze used in this study was a black circular pool $(180 \mathrm{~cm}$ in diameter) filled to a $40 \mathrm{~cm}$ depth with $24^{\circ} \mathrm{C}$ water. The black platform $(10 \mathrm{~cm}$ in diameter) was hidden $2 \mathrm{~cm}$ below the water surface in the SW quadrant. On each day, rats were given four successive trials with a maximum duration of $90 \mathrm{sec}$, the inter-trial interval was 1 minute. Starting points (N, E, NW, SE) were randomized (Vorhees \& Williams, 2006). Multiple color distal cues were placed on the wall and remained there throughout the experiment. Performance was recorded and analyzed by the EthoVision software (Noldus, Wageningen, Netherlands).

\section{Isolation of total RNA from the hippocampus}

At the completion of the experiment, animals were deeply anaesthetized with a mixture of ketamine and xylazine (50 mg/kg ketamine, $10 \mathrm{mg} / \mathrm{kg}$ xylazine). After collection of CSF from the cisterna magna, animals for gene expression analysis were transcardially perfused with icecold PBS containing 10\% RNAlater (Invitrogen, Carlsbad, CA, USA). Brains were quickly removed from the skull and placed into an ice-cold RBM-4000C rat brain matrix (ASI 
Instruments, Warren, MI, USA). A $4 \mathrm{~mm}$ thick coronal slice was dissected with two blades positioned at bregma -2.2 and -6.2. Hippocampal formations were dissected from this slice. Samples were collected in Eppendorf tubes containing $1 \mathrm{ml}$ of ice-cold RNAlater, incubated on ice for 1 hour, frozen on dry ice and stored at $-80^{\circ} \mathrm{C}$. Total RNA was isolated using the RNeasy Lipid Tissue Mini Kit (Qiagen, Hilden, Germany). RNA analytics included capillary electrophoresis using Nano RNA Chips on 2100 Bioanalyzer (Agilent, Santa Clara, CA, USA). cDNA synthesis was performed using the High Capacity cDNA Reverse Transcription Kit according to manufacturer's instructions (Applied Biosystems, Foster City, CA, USA).

\section{Real-time PCR}

TaqMan inventoried gene expression assays (Applied Biosystems) were used to study transcriptional regulation of 75 selected genes by real-time PCR. Glyceraldehyde-3-phosphate dehydrogenase (Gapdh), hypoxanthine phosphoribosyl-transferase (Hprt1) and peptidyl-prolyl isomerase A (Ppia) were used as house-keeping genes. Each assay consisted of a FAM dyelabeled TaqMan MGB probe and two PCR primers. Real-time PCR was performed on a ViiA7 Real-Time PCR System (Applied Biosystems) as described earlier (Sarvari, Kallo, Hrabovszky, Solymosi, \& Liposits, 2014). The ViiA7 RUO software and relative quantification against calibrator samples $(\Delta \Delta \mathrm{Ct})$ were used for data analysis. A computed internal control corresponding to the geometric mean of $\mathrm{Ct}$ values of selected house-keeping genes was used for $\Delta \mathrm{Ct}$ calculation. Relative quantity $\left(\mathrm{RQ}=2^{-\Delta \Delta \mathrm{Ct}}\right)$ was used to characterize gene expression in the various experimental groups. PCR experiments conformed to minimum information for publication of quantitative real-time PCR experiments (MIQE) guidelines (Bustin et al., 2009).

\section{Immunohistochemistry}

After behavioural tests, animals were deeply anaesthetized with a mixture of ketamine and xylazine, and CSF was collected from the cisterna magna. Three rats per group were perfused transcardially with PBS followed by $120 \mathrm{ml}$ of $4 \%$ paraformaldehyde (PFA) in $0.1 \mathrm{M}$ PBS. Brains were quickly removed from the skull and post-fixed overnight in $4 \%$ PFA. Brains were cryoprotected overnight in $30 \%$ sucrose and frozen on powdered dry ice. Coronal, $30 \mu \mathrm{m}$ thick sections were prepared using a freezing microtome (SMR2000R, Leica Biosystems, Nussloch, Germany). Sections were collected into a series of six wells, thus each well contained consecutive sections that were $180 \mu \mathrm{m}$ apart rostro-caudally from one another.

For Iba1 immunohistochemistry (IHC), after pretreatment with a solution containing $0.5 \%$ Triton X-100 and $0.5 \% \mathrm{H}_{2} \mathrm{O}_{2}$ in PBS for 20 minutes, sections were immersed in a rabbit polyclonal antiserum against Iba1 (1:2,000 dilution, \#019-19741, Wako Chemicals) for 72 hours at $4^{\circ} \mathrm{C}$, followed by 1 -hour incubations in biotin conjugated anti-rabbit IgG (1:500 
dilution, Jackson ImmunoResearch Laboratories, West Grove, PA, USA) and ABC elite reagent (1:1,000 dilution, Vector Laboratories, Burlingame, CA, USA). The immunoreaction product was visualized with nickel-enhanced diaminobenzidine $\left(0.15 \% \mathrm{NiNH}_{4} \mathrm{SO}_{4}, 0.005 \% \mathrm{H}_{2} \mathrm{O}_{2}\right.$, $0.05 \%$ diaminobenzidine in Tris pH7.6). Sections were mounted on glass slides and coverslipped with DPX mounting medium (VWR, Radnor, PA, USA). Slides were analyzed using a Zeiss Axioskop-2 (Carl-Zeiss Microscopy, Jena, Germany) microscope. Sections were photographed with an AxioCam HRc digital camera controlled by AxioVision 4.6 software (Carl-Zeiss). Digital pictures were taken using 20x and 40x objectives.

For immunofluorescent detection of $A \beta_{1-42}$, sections were pretreated with a solution containing $1 \%$ human serum albumin, $0.1 \%$ Triton $\mathrm{X}-100$ and $1 \mathrm{mg} / \mathrm{ml}$ digitonin for 1 hour and incubated with mouse monoclonal antibody against $A \beta_{1-42}$ (\#126649, Abcam) at the dilution of 1:200 for 72 hours at $4^{\circ} \mathrm{C}$. Cy3-conjugated anti-mouse $\operatorname{IgG}$ (1:500 dilution, Jackson ImmunoResearch Laboratories) was diluted in PBS containing 2\% normal horse serum and applied on the sections for 2 hours. Similarly prepared sections from the cerebral cortex of APP ${ }^{\text {NL-F/NL-F }}$ mice (Nilsson, Saito, \& Saido, 2014) were used as positive controls. Sections were mounted on glass slides and coverslipped with VectaShield mounting medium (Vector Laboratories). Slides were investigated using a Zeiss Axioskop-2 microscope under epifluorescent illumination using a filter set for $\mathrm{Cy} 3$ dye. Specificity of the $\mathrm{A} \beta_{1-42}$ antibody was confirmed by the lack of staining on wild-type mouse tissue, and the characteristic staining in $\mathrm{APP}^{\mathrm{NL}-\mathrm{F} / \mathrm{NL}-\mathrm{F}}$ mice with $\mathrm{A} \beta$ plaques.

\section{Cytometric bead array}

The measurement of rat IFN $\gamma$, IL-1 $\alpha$, IL-10 and TNF $\alpha$ was performed by cytometric bead array (CBA) as earlier (Denes et al., 2015), using BD ${ }^{\mathrm{TM}}$ CBA Flex Sets (BD Biosciences, Franklin Lakes, NJ, USA) according to manufacturer's protocol. Samples were acquired on a BD FACSVerse $^{\mathrm{TM}}$ flow cytometer and data analyzed using FCAP Array v3 software (BD Bioscience).

\section{Statistics}

In PCR data evaluation, group data were expressed as relative quantity: RQ(mean) \pm standard deviation. Statistical significance of the changes in gene expression was analyzed using oneway ANOVA followed by Newman-Keuls post-hoc test (Statistica 13.1, Dell Software, Round Rock, TX, USA). In the assessment of MWM data, we used one-way ANOVA with NewmanKeuls post-hoc test to determine probability of the changes. Differences were considered significant at $\mathrm{p}<0.05$. 


\section{Results}

\section{AßO infusion evoked lasting microglial activation and inflammation in the hippocampus}

We characterized changes of the microglia phenotype in the hippocampus after intracerebroventricular (icv.) infusion $\mathrm{A} \beta \mathrm{O}$ and artificial CSF by measuring the expression of $\mathrm{Ibal}, \mathrm{Cd} 1 \mathrm{lb}$, Cd68, Cd80, Cd86 and RT1-EC2 (Fig. 1A-F). All selected microglia reactivity markers were upregulated in the $\mathrm{A} \beta \mathrm{O}$ challenged group compared to controls. IHC and quantitative evaluation of Iba1 immunoreactivity were performed to verify the presence of activated microglia (Fig. 1G). In accordance with elevated expression of reactivity marker genes, Iba1 integrated density was significantly higher in the CA1 region of animals challenged with $A \beta O$ compared to controls. To characterize further the microglia phenotype, we investigated mRNA expression of a set of microglia related genes encoding receptors for recognition, recruitment and phagocytosis (Table 1). Expression of all selected recognition (Tlr2, Tlr3, Tlr4, Tlr9, coreceptor Cd14), recruitment (C3ar1, C5ar1, Ccr2, Cxcr4), phagocytic and scavenger receptor genes (Cd11b, Cd11c, Cd163, Cd18, Cd68, Crry, Fcgr1a, Fcgr2a, Fcgr2b, Fcgr3a, Mfge8, $M r c 1)$ was enhanced in the $\mathrm{A} \beta \mathrm{O}$ challenged group compared to controls.

MCC950 treatment after $A \beta O$ infusion reversed mRNA expression of all selected reactivity marker genes (Fig. 1A-F). MCC950 also decreased Iba1 integrated density (Fig. 1G) supporting the results of gene expression analysis described above. MCC950 fully reversed upregulation of recognition, recruitment and phagocytosis receptor genes (Table 1).

We studied expression of selected chemokine, complement and cytokine genes, some of them related to the status of the transcription factor NF- $\kappa \mathrm{B}$ (Table 2). Infusion of A $\beta O$ and CSF robustly enhanced chemokine $(C c l 2, C x c l 10)$ and complement $(C 3, C f b)$ expression in the hippocampus. A $\beta \mathrm{O}$ also increased Nlrp3 and $I l 1 b$ expression indicating activation of NF- $\kappa \mathrm{B}$. Upregulation of additional proinflammatory cytokines (Tnf, Ill2b) and Nos2 supported the notion that microglia remained activated after icv. infusion of $A \beta O$ and CSF. On the other hand, icv. infusion of MCC950 immediately after A $3 \mathrm{O}$ infusion reduced expression of all proinflammatory genes to control levels (Table 2) indicating that the NLRP3 inhibitor abolished $\mathrm{NF}-\kappa \mathrm{B}-$ dependent transcriptional activation.

We couldn't detect extracellular $A \beta_{1-42}$ plaques in the hippocampus after $A \beta O$ and $C S F$ infusion (Fig. 2), although we detected $A \beta_{1-42}$ immunoreactivity in the cerebral cortex of APP ${ }^{\text {NL-F/NL-F }}$ mice (Nilsson et al., 2014). This finding indicated that microglia may have contributed to the elimination of $\mathrm{A} \beta \mathrm{O}$ or prevented its accumulation in the brain, but remained activated after A $\beta O$ challenge. 


\section{A $\beta O$ infusion activated transcription of genes related to neuronal control of microglia}

Neurons control microglia reactivity by neuronal inhibitory ligands via their cognate microglial receptors (Hanisch \& Kettenmann, 2007; Tian, Rauvala, \& Gahmberg, 2009). After A $\beta O$ and CSF infusion, expression of $C x 3 c l 1$ (Fig. 3A), $C d 200$ (Fig. 3B), and $C d 22$ (Fig. 3C) increased moderately, while their cognate microglial receptors, Cx3crl (Fig. 3D), Cd200rl (Fig. 3E), and Cd45 (Fig. 3E) enhanced robustly compared to controls. Expression of other neuronal inhibitory ligands such as $\mathrm{Cd} 47(\mathrm{RQ}=1.67 \pm 0.33, \mathrm{p}=0.01)$ and Sema3a $(\mathrm{RQ}=1.63 \pm 0.15$, $\mathrm{p}=0.001$ ) elevated moderately. Transcription of $C d 86$, which is a key player in the modulation of the microglia phenotype (Louveau et al., 2015), also enhanced significantly (Fig. 1E). MCC950 treatment restored expression of both neuronal ligands and their microglial receptors (Fig. 3).

\section{AßO infusion altered expression of estrogen receptor genes}

Estradiol is synthesized from testosterone by aromatase in the hippocampus. Its effects are mediated by estrogen receptors, mainly via estrogen receptor alpha $(\mathrm{ER} \alpha)$ and beta $(\mathrm{ER} \beta)$, which are encoded by Esrl and Esr2, respectively. A $\beta O$ challenge inversely regulated the expression of estrogen receptors, decreased Esrl (Fig. 4A) and increased Esr2 (Fig. 4B) expression. Inhibition of NLRP3 inflammasome activation restored Esrl mRNA expression and attenuated upregulation of Esr2.

\section{AßO infusion suppressed Scn Ia mRNA expression}

Interneuron-specific and parvalbumin-positive basket cell predominant voltage-gated sodium channel subunit Nav1.1 shows decreased expression in AD (Verret et al., 2012). As the process takes place at early phase of the disease, we followed mRNA expression Scnla encoding the $\mathrm{Na}(\mathrm{v}) 1.1$ subunit in the hippocampus after icv. infusion A $\beta O$ and CSF. Scnla expression was decreased $(\mathrm{RQ}=0.79 \pm 0.02, \mathrm{p}=0.032)$, but MCC950 restored $\operatorname{Scn} 1 a(\mathrm{RQ}=0.95 \pm 0.06)$ expression, although the change did not reach statistical significance $(\mathrm{p}=0.09)$.

\section{AßO infusion leads to impaired spatial memory}

Hippocampus-dependent spatial memory was tested in MWM tasks. During spatial acquisition, decreasing escape latency times indicated fast spatial learning in the case of the control groups from day 2 (Fig. 5A). Vehicle and drug control groups showed indistinguishable parameters, therefore only latency times of the vehicle control group were shown. The A $\beta O$ challenged group showed higher latency times than controls from day 2, and the difference became statistically significant on day 4 (Fig. 5A).

On day 5, the hidden platform was moved to the opposite quadrant (reversal) and spatial acquisition was followed for three days (Fig. 5B). Control animals learned the new position of 
the platform fast, while the $\mathrm{A} \beta \mathrm{O}$ challenged group showed impaired learning. The difference between latency times reached statistical significance on day 3 (Fig. 5B).

In the MCC950 treatment group, we measured decreased latency times compared to the A $\beta O$ challenged group, similar to control groups (Fig. 5A). After reversal, the MCC950 treatment group learned the new position of the platform fast, while the $\mathrm{A} \beta \mathrm{O}$ challenged group showed impaired learning (Fig. 5B). The performance of control groups and the MCC950 treatment group was similar (and was not different statistically) indicating that MCC950 completely reversed $\mathrm{A} \beta \mathrm{O}$-evoked memory impairments.

Blockade of the NLRP3 inflammasome reversed ABO-induced decreases in serum IL-10 Activation of microglia and the NLRP3 inflammasome may influence immune-related cells in the circulation. Therefore, we investigated serum cytokine profiles by measuring concentrations of IL-1 $\alpha$, TNF $\alpha$, IL-10 and IFN $\gamma$. TNF $\alpha$ and IFN $\gamma$ levels were below the detection limit of the CBA assay. In contrast to the low serum levels of proinflammatory cytokines, concentrations of IL-10 (Fig. 6A) were $105 \pm 1.7 \mathrm{pg} / \mathrm{ml}$ in control animals, which decreased to $83 \pm 14.0 \mathrm{pg} / \mathrm{ml}$ in $\mathrm{A} \beta \mathrm{O}$ challenged animals, but the change did not reach statistical significance $(\mathrm{p}=0.064)$. MCC950 treatment normalized serum IL-10. Serum levels of IL-1 $\alpha$ (Fig. 6B) showed no difference among treatment groups. 


\section{Discussion}

The microglia driven innate immune response against $\mathrm{A} \beta \mathrm{O}$ in the hippocampus is implicated in the pathogenesis of late-onset AD (Akiyama et al., 2000; Heneka et al., 2015; Lucin \& WyssCoray, 2009). To explore the $\mathrm{A} \beta \mathrm{O}$-induced microglia response and putative downstream mechanisms acting in the aging hippocampus, we induced an early AD-like neurological phenotype in middle-aged male rats by $\mathrm{A} \beta \mathrm{O}$ (and CSF) infusion into the lateral cerebral ventricle. Then, we studied spatial memory, as well as selected molecular elements of the innate immune response and interneuron-related processes. To clarify the impact of the microglia driven innate immune response to $\mathrm{A} \beta \mathrm{O}$ on spatial memory impairment in our middle-aged infusion model, we blocked activation of the NLRP3 inflammasome by icv. infusion of MCC950.

Infusion of $A \beta_{1-40}$ and $A \beta_{1-42}$ into the cerebral ventricles of middle-aged rats is an established approach to mimic the neurological phenotype of late-onset AD (Frautschy et al., 2001; Frautschy et al., 1996). As familial AD mutations lead to increased $A \beta_{1-42}$ : $A \beta_{1-40}$ ratio (Hardy, 1997), and $A \beta_{1-40}$ and $A \beta_{1-42}$ are the predominant species in neuritic plaques of $A D$ patients (Masters et al., 1985; Mori, Takio, Ogawara, \& Selkoe, 1992), we chose $A \beta_{1-42}$ to form oligomers. Of note, structure and composition of $\mathrm{A} \beta \mathrm{O}$ are markedly different from the neurotoxic oligomers of $A \beta_{1-40}$ (Ahmed et al., 2010). This structural difference goes with distinct prefibrillar to fibrillar oligomer transitions, and while $\mathrm{A} \beta \mathrm{O}$ are stable at low temperature and low ionic strength, $A \beta_{1-40}$ oligomers slowly form protofibrils and fibrils under the same condition (Ahmed et al., 2010; Glabe, 2008). Our oligomer preparation under low temperaturelow salt condition results in mainly pentamers (and decamers), but we cannot exclude the possibility that the structure and composition of $\mathrm{A} \beta \mathrm{O}$ may change during infusion, although we found no sign of fibril formation. Using expression analysis and evaluation of Iba1 immunoreactivity, we provided evidence that 4 weeks after $A \beta O$ infusion still there is microglia activation in the hippocampus (Fig. 1). Although extracellular $A \beta_{1-42}$ plaques were not present (Fig. 2), we found evidence for upregulation of chemokines, complement and proinflammatory cytokines indicating the activation of NF- $\mathrm{BB}$ (Table 2). Robust transcriptional activation of genes encoding $\mathrm{C} 3-\mathrm{Cd} 11 \mathrm{~b} / \mathrm{Cd} 18$ ligand-receptor pairs indicated increased microglial phagocytosis. In accordance, upregulated production and activation of complement have been demonstrated in the AD brain (Eikelenboom \& Stam, 1982; Yasojima, Schwab, McGeer, \& McGeer, 1999). Early activation of complement in AD has been proved recently (Hong et al., 2016; Zanjani et al., 2005). Upregulation of complement genes in the hippocampus after icv. 
infusion A $\beta O$ (Table 2) lends further support for the role of complement in early AD. Although we observed enhanced expression of some microglia receptors and their neuronal inhibitory ligands (Fig. 3), regulatory mechanisms were unable to prevent microglia activation after the encounter with $\mathrm{A} \beta \mathrm{O}$. Uncontrolled microglia activation coincided with downregulation of Esrl (Fig. 4) and Scnla expression, and impairment of spatial memory (Fig. 5).

Estradiol is synthesized from testosterone by aromatase in the hippocampus (Hojo et al., 2004). Its effects are mediated by estrogen receptors, mainly via ER $\alpha$ and ER $\beta$, both of them are expressed in the rat hippocampus (Shughrue \& Merchenthaler, 2000). In microglia, the expression of $E R \alpha$ and $\operatorname{ER} \beta$ is still controversial. While both have been observed in vitro, only $\mathrm{ER} \alpha$ has been observed in vivo (Sierra, Gottfried-Blackmore, Milner, McEwen, \& Bulloch, 2008). We found downregulation of Esrl indicating possible impairment of powerful microglia-dependent anti-inflammatory mechanisms (Vegeto et al., 2003). The regulatory role of ER $\alpha$-mediated E2 action in neuroinflammation and NLRP3 inflammasome activation remains largely unexplored in $\mathrm{AD}$. On the other hand, reduced ER $\alpha$ expression may also have an impact on neuromodulation (B. McEwen et al., 2001), as ER $\alpha$ is localized in dendrites, dendritic spines, and presynaptic terminals (B. S. McEwen, Akama, Spencer-Segal, Milner, \& Waters, 2012). ER $\alpha$ mediates translational regulation of synaptogenesis via activating protein synthesis for dendritic function (Akama \& McEwen, 2003). In addition, ER $\alpha$, associated with clusters of vesicles in perisomatic inhibitory boutons, regulates vesicle trafficking at inhibitory synapses (Hart, Snyder, Smejkalova, \& Woolley, 2007). These effects make E2 a powerful regulator of the hippocampus. Cessation of ovarian E2 synthesis renders the hippocampus vulnerable to $\mathrm{A} \beta \mathrm{O}$ and may contribute to the increased risk of $\mathrm{AD}$ in postmenopausal women (Henderson \& Buckwalter, 1994). Decreased mRNA expression of ER $\alpha$ isoforms (Ishunina, Fischer, \& Swaab, 2007) and reduced number of both cytoplasmic and nuclear ER $\alpha$ positive neurons (Hu et al., 2003) have been reported in the AD hippocampus. We found downregulation of Esr 1 indicating impairment of powerful anti-inflammatory mechanisms (Vegeto et al., 2003) and neuromodulation (B. McEwen et al., 2001). ERa is localized at both nuclear and extranuclear sites of the hippocampus and expressed in dendrites, dendritic spines, presynaptic terminals and glial processes (B. S. McEwen, Akama, Spencer Segal, Milner, \& Waters, 2012). ERa mediates translational regulation of synaptogenesis via activating protein symthesis for dendritic function (Akama \& McEwen, 2003). In addition, ERa, associated with clusters of vesicles in perisematic inhibitory boutons, regulates vesicle trafficking at inhibitory synapses (Hart, Snyder, Smejkalova, \& Woølley, 2007). Importantly, decreased mRNA expression of 
ERa isoforms (Ishunina, Fischer, \& Swaab, 2007) and reduced number of both cytoplasmic and nuclear ER a positive neurons (Hu et al., 2003) has been reported in the AD hippocampus. Scnla, which encodes the voltage-dependent sodium channel alpha subunit $\mathrm{Na}(\mathrm{v}) 1.1$ expressed predominantly in parvalbumin-positive basket cells, is downregulated in AD brains at both mRNA and protein levels (Verret et al., 2012). The relationship between reduced $\mathrm{Na}(\mathrm{v}) 1.1$ expression, hypersynchrony and memory impairment has been established in AD (Verret et al., 2012). AßO-induced downregulation of Esrl and Scnla may interfere with the function of inhibitory interneurons, which represent a link between NLRP3 inflammasome activation and memory decline. A $\beta O$-mediated memory decline became significant on the $4^{\text {th }}$ day of spatial acquisition in MWM (Fig. 5), in accord with other studies using the middle-aged rat infusion model (Frautschy et al., 2001).

We found that inhibition of the NLRP3 inflammasome by icv. infusion of MCC950 after A $\beta O$ challenge attenuated A $\mathrm{OO}-\mathrm{evoked}$ microglia reactivity (Fig. 1) and NF- $\mathrm{KB}$ activation, and abolished spatial memory impairment (Fig. 5). These observations agree with the results of recent pharmacological studies in APP transgenic mouse models (Daniels et al., 2016; Dempsey et al., 2016). An important novel observation that adds to these earlier studies is that $A \beta O$ is sufficient to induce long-lasting inflammation and memory deficits in an NLRP3-dependent manner, even in the absence of major amyloid deposits in the brain parenchyma. In addition, we found that MCC950 restored transcriptomic changes of genes involved in neuron-microglia communication, and reversed downregulation of Esrl and Scnla, although in the latter case the effect did not reach statistical significance. As MCC950 infusion leads to the resolution of inflammation and restoration of spatial memory, it is likely that A $\beta O$-evoked inflammatory responses play causative role in the suppression of estrogen signaling, alteration of basket cell specific sodium transport and impairment of spatial memory. Based on these findings, we propose that $\mathrm{A} \beta \mathrm{O}$ activates microglia, which persists even after the elimination of the pathogenic substance. Enduring activation of microglia interferes with ER $\alpha$ signaling and subunit composition of voltage-gated sodium channels in basket cells among others, resulting in reversible impairment of spatial learning and memory.

Central inflammatory reactions may have an impact on the peripheral immune system, and vice versa. Cognitively impaired patients with amyloidosis have shown higher serum levels of proinflammatory cytokines and lower levels of IL-10 compared to patients without brain amyloidosis (Cattaneo et al., 2017). Therefore, activation of microglia in the hippocampus may influence immune-related cells in the circulation and alter the serum cytokine profiles. Although statistical significance was not achieved in our study, serum levels of IL-10 tended to 
decrease in middle-aged rats following $\mathrm{A} \beta \mathrm{O}$ challenge (Fig. 6). We demonstrated that serum levels of IL 10 were decreased in middle aged rats following $\Lambda \beta O$ challenge (Fig. 6). Importantly, serum IL-10 levels are affected in individuals with AD (Asselineau et al., 2015; Remarque et al., 2001; Swardfager et al., 2010). In peripheral blood mononuclear cells, IL-10 synthesis is almost ceased in fast cognitive decliners, whereas its level is slightly increased in slow cognitive decliners with AD (Asselineau et al., 2015). In our middle-aged rat infusion model, MCC950 restored normal serum IL-10 levels (Fig. 6). This finding gives support to the idea that $\mathrm{A} \beta \mathrm{O}$-induced microglia activation results in a decrease in serum IL-10 levels. Emerging evidence indicates that IL-10 acts in a negative feedback loop to regulate the NLRP3 inflammasome during chronic stimulations (Gurung et al., 2015; Ip, Hoshi, Shouval, Snapper, \& Medzhitov, 2017; Yao et al., 2015). A very recent paper has demonstrated that IL-10 promotes mitophagy that eliminates dysfunctional mitochondria in macrophages (Ip et al., 2017). However, the functional contribution of IL-10 to the transcriptomic, inflammatory and behavioral changes observed has not been tested in this study. This finding gives support to the idea that $\Lambda \beta O$-induced microglia activation results in a decrease in serum It 10 levels. Proinflammatory cytokine TNFa were undetectable in the sermm, while It $1 a$ levels showed no difference among the experimental groups.

In conclusion, these results demonstrate that icv. infusion of $A \beta O$ evokes lasting microglial and inflammatory responses in the hippocampus of middle-aged rats leading to reversible impairment of spatial memory. The underlying mechanisms might include interference with Esrl and Scnla expression in the hippocampus, and peripheral IL-10-mediated action could potentially contribute to the changes observed, which will need to be tested in further studies. 


\section{Acknowledgements}

The authors thank Dr. Gábor Mező (Department of Organic Chemistry, Eötvös University, Budapest, Hungary) for his help in the preparation of $A \beta_{1-42}$ oligomers, and members of the Behavioral Study Unit of Institute of Experimental Medicine for support in MWM experiments. This work was supported by the National Brain Research Program for CF (KTIA_13_NAP_A_1/3), the 'Momentum' Program of Hungarian Academy of Sciences for ÁD (LP2016-4/2016), the Hungarian Scientific Research Fund for EH and ZL (OTKA 112669, OTKA K115984), the National Research, Development \& Innovation Office for GN (VKSZ 14-1-2015_0155) and the Theme Program of Gedeon Richter Plc. for MS (TP8-005).

\section{Authors' contributions}

MS designed the study with CF and ZL. CF performed surgeries, CF, CV, EH, IK and MS collected tissues and samples. MS run and analyzed MWM and real-time PCR. CV performed and analyzed Ibal IHC in conjunction with EH. CV performed A $\beta 1-42$ IHC together with GN. ÁD run and analyzed CBA and provided conceptual support for these studies. MS wrote the manuscript with editing from all other authors. All authors read and approved the final version of the manuscript. 


\section{Tables}

Table 1 Expression of recognition, recruitment and phagocytosis receptors associated with microglia in the rat hippocampus after A $\beta O$, artificial CSF and MCC950 infusions.

$\mathrm{A} \beta \mathrm{O}+\mathrm{aCSF}$

\begin{tabular}{lllllll} 
Gene & RQ & SD & $p$ & RQ & SD & $p$ \\
\hline \multicolumn{1}{c}{ Recognition } & & & & & & \\
\hline Cd14 & 5.32 & 1.99 & 0.005 & 1.77 & 0.35 & 0.399 \\
TIr2 & 2.48 & 0.80 & 0.004 & 0.77 & 0.23 & 0.651 \\
TIr3 & 3.20 & 1.09 & 0.003 & 0.88 & 0.18 & 0.741 \\
TIr4 & 1.80 & 0.33 & 0.002 & 0.84 & 0.22 & 0.548 \\
TIr9 & 1.76 & 0.38 & 0.020 & 0.87 & 0.05 & 0.586 \\
& & & & & &
\end{tabular}

\begin{tabular}{lllllll}
\hline \multicolumn{1}{c}{ Recruitment } & & & & & & \\
\hline C3ar1 & 1.77 & 0.39 & 0.005 & 0.76 & 0.21 & 0.321 \\
C5ar1 & 3.00 & 1.48 & 0.027 & 1.02 & 0.32 & 0.965 \\
Ccr2 & 5.09 & 1.55 & 0.002 & 0.56 & 0.28 & 0.625 \\
Cxcr4 & 1.73 & 0.28 & 0.003 & 0.84 & 0.17 & 0.288 \\
& & & & & & \\
\hline \multicolumn{1}{c}{ Phagocytosis } & & & & & & \\
\hline Cd11b & 4.12 & 1.29 & 0.000 & 0.79 & 0.21 & 0.494 \\
Cd11c & 14.37 & 6.80 & 0.033 & 1.99 & 0.75 & 0.850 \\
Cd163 & 1.63 & 0.22 & 0.012 & 0.97 & 0.03 & 0.893 \\
Cd18 & 2.80 & 0.49 & 0.001 & 0.83 & 0.14 & 0.579 \\
Cd68 & 3.52 & 1.17 & 0.005 & 0.89 & 0.33 & 0.867 \\
Crry & 1.31 & 0.09 & 0.006 & 0.83 & 0.13 & 0.043 \\
Fcgr1a & 3.81 & 0.83 & 0.001 & 1.01 & 0.28 & 0.993 \\
Fcgr2a & 1.89 & 0.26 & 0.001 & 1.17 & 0.18 & 0.222 \\
Fcgr2b & 4.14 & 1.31 & 0.006 & 1.17 & 0.28 & 0.827 \\
Fcgr3a & 5.85 & 1.60 & 0.001 & 0.90 & 0.19 & 0.900 \\
Mfge8 & 1.24 & 0.06 & 0.043 & 0.99 & 0.14 & 0.716 \\
Mrc1 & 2.09 & 0.18 & 0.001 & 0.90 & 0.22 & 0.519 \\
& & & & & & \\
\hline
\end{tabular}

Twenty-one genes, encoding microglia receptors involved in recognition, recruitment and phagocytosis, were selected and studied by quantitative real-time PCR. AßO- and MCC950evoked changes were compared to controls. One-way ANOVA with Newman-Keuls post-hoc test was used for statistical analysis. In the case of A $\mathrm{O}+\mathrm{MCC} 950, \mathrm{p}$ values greater than 0.05 show that mRNA expression of genes in drug treated animals did not differ from controls. RQ, relative quantity; $\mathrm{SD}$, standard deviation; $\mathrm{p}$, probability. 
Table 2 Expression of selected chemokine, complement and cytokine genes in the hippocampus after $\mathrm{A} \beta \mathrm{O}$, artificial $\mathrm{CSF}$ and MCC950 infusions.

\begin{tabular}{|c|c|c|c|c|c|c|}
\hline \multirow[b]{2}{*}{ Gene } & \multicolumn{3}{|c|}{$A \beta O+a C S F$} & \multicolumn{3}{|c|}{$A \beta O+M C C 950$} \\
\hline & $\mathrm{RQ}$ & SD & $\mathrm{p}$ & $\mathrm{RQ}$ & SD & $p$ \\
\hline \multicolumn{7}{|c|}{ Chemokines } \\
\hline $\mathrm{Ccl} 2$ & 10.88 & 1.91 & 0.000 & 1.58 & 0.32 & 0.667 \\
\hline Cxcl10 & 4.22 & 0.69 & 0.001 & 0.92 & 0.26 & 0.806 \\
\hline Cxcl12 & 1.09 & 0.20 & & 1.05 & 0.16 & \\
\hline \multicolumn{7}{|c|}{ Complement } \\
\hline C3 & 7.62 & 4.37 & 0.011 & 0.86 & 0.54 & 0.979 \\
\hline $\mathrm{Cfb}$ & 10.84 & 3.08 & 0.001 & 0.93 & 0.22 & 0.996 \\
\hline Cfd & 2.13 & 0.09 & 0.000 & 0.96 & 0.04 & 0.609 \\
\hline Cfh & 1.87 & 0.24 & 0.000 & 0.98 & 0.15 & 0.960 \\
\hline Cfp & 1.58 & 0.11 & 0.000 & 1.02 & 0.13 & 0.944 \\
\hline $\mathrm{Clu}$ & 1.22 & 0.09 & 0.104 & 0.78 & 0.18 & 0.110 \\
\hline Serping1 & 3.70 & 0.90 & 0.000 & 0.84 & 0.17 & 0.715 \\
\hline \multicolumn{7}{|c|}{ Cytokines } \\
\hline$\| 1 \mathrm{~b}$ & 1.99 & 0.58 & 0.004 & 0.84 & 0.42 & 0.584 \\
\hline$\| 10$ & 1.32 & 0.18 & & 0.63 & 0.19 & \\
\hline$\| 12 b$ & 4.32 & 0.65 & 0.008 & 1.21 & 0.86 & 0.887 \\
\hline 116 & 1.22 & 0.19 & & 0.91 & 0.04 & \\
\hline Tgfb1 & 2.04 & 0.10 & 0.000 & 0.96 & 0.25 & 0.648 \\
\hline Tnf & 3.62 & 0.28 & 0.000 & 0.96 & 0.18 & 0.696 \\
\hline \multicolumn{7}{|l|}{ Other } \\
\hline Nlrp3 & 1.87 & 0.12 & 0.000 & 0.83 & 0.10 & 0.143 \\
\hline Nos2 & 12.00 & 1.24 & 0.000 & 0.57 & 0.57 & 0.532 \\
\hline
\end{tabular}

Eighteen genes encoding chemokines, complement and cytokines were selected and studied by quantitative real-time PCR. A $3 \mathrm{O}-$ and MCC950-induced changes were compared to controls. One-way ANOVA with Newman-Keuls post-hoc test was used for statistical analysis. RQ, relative quantity; $\mathrm{SD}$, standard deviation; $\mathrm{p}$, probability. 


\section{Legends to figures}

Figure 1 Infusion of $\mathrm{A} \beta \mathrm{O}$ and $\mathrm{CSF}$ enhanced microglia reactivity in the hippocampus. $\mathrm{A} \beta \mathrm{O}(\mathrm{A}+\mathrm{CSF}, \mathrm{n}=6)$ increased mRNA expression of microglial reactivity marker genes (A) Aif1/Iba1, (B) Cd11b/Itgam, (C) Cd68, (D) Cd80, (E) Cd86 and (F) RT1-EC2 compared to controls (CTRL). MCC950 treatment (A+DRUG, $\mathrm{n}=8$ ) attenuated A $\beta O$-induced upregulation of all marker genes. Quantitative real-time PCR with inventoried gene expression assays were applied to determine mRNA levels in $\mathrm{A} \beta \mathrm{O}$ plus aCSF (A+CSF), A $\beta O$ plus MCC950 $(\mathrm{A}+\mathrm{DRUG})$ and control groups (CTRL). One-way ANOVA with Newman-Keuls post-hoc test was used to determine statistical significance (asterisks). (G) Iba1 IHC in the CA1 region of the rat hippocampus. Using Iba1 immunostaining we demonstrated A $\beta O$-evoked changes of the microglia phenotype. The alteration manifested primarily in the enhanced Iba1 integrated density in microglia.

Figure $2 A \beta_{1-42}$ immunohistochemistry. Detection of $A \beta_{1-42}$ immunoreactivity in the cerebral cortex of (A) middle-aged control rats, (B) A $\beta O$ challenged middle-aged rats, $(\mathbf{C}) 11$ months old wild-type mice and (D) APP ${ }^{\mathrm{NL}-\mathrm{F} / \mathrm{NL}-\mathrm{F}}$ mice. Arrows mark strong A $\beta_{1-42}$ immunoreactivity indicating the presence of extracellular $A \beta$ plaques. Scale bar is $50 \mu \mathrm{m}$.

Figure $3 \quad A \beta O$ infusion enhanced mRNA expression of genes involved in neuronal control of microglia reactivity. $\mathrm{A} \beta \mathrm{O}$ challenge $(\mathrm{A}+\mathrm{CSF}, \mathrm{n}=6$, black column) activated transcription of (A) Cx3cl1, (B) Cd200, (C) Cd22, (D) Cx3crl, (E) Cd200r and (F) Cd45 compared to controls (CTRL, white column). MCC950 treatment (A+DRUG, $n=8$, striped column) abated transcriptional activation of all genes encoding neuronal inhibitory ligands and their cognate microglial receptors. Gene expression was determined by quantitative real-time PCR. One-way ANOVA with Newman-Keuls post-hoc test was used to evaluate statistical significance.

Figure $4 \mathrm{~A} \beta \mathrm{O}$ challenge altered the expression of estrogen receptor genes. (A) $\mathrm{A} \beta \mathrm{O}$ (A+CSF, black column) decreased mRNA expression of Esrl compared to controls (CTRL, white column). MCC950 (A+DRUG, striped column) restored Esrl expression. (B) A $\beta O$ increased mRNA expression of Esr2 compared to controls. Inhibition of NLRP3 inflammasome attenuated upregulation of Esr2.

Figure 5 Morris water maze tasks, (A) spatial acquisition and (B) reversal, revealed impairments of spatial memory. A $\beta O$ challenged (A+CSF, black solid line, $n=6$ ), controls (CTRL, grey, $n=6$ ) and A 30 plus MCC950 (A+DRUG, black dashed line, $n=8$ ) groups were examined, and displayed mean of the latencies in relation to the trial number. On each day, rats were given four consecutive trials of a maximum duration of $90 \mathrm{sec}$. Control (CTRL) and drug 
control (VEH+DRUG) groups performed identically, therefore only data of the control group were shown. One-way ANOVA with Newman-Keuls post-hoc test was used for statistical analysis.

Figure 6 Infusion of $\mathrm{A} \beta \mathrm{O}$ had an impact on serum cytokine profile. (A) A $\beta O$ challenge (A+CSF, $n=6$, black column) decreased serum IL-10 levels compared to controls (CTRL, $n=6$, white column), although the change did not reach statistical significance $(p=0.064)$. MCC950 after $\mathrm{A} \beta \mathrm{O}$ infusion (A+DRUG, $\mathrm{n}=8$, striped column) reversed declining serum levels of IL-10. (B) There was no change in IL-1 $\alpha$ levels among treatment groups. Serum IL-10 levels were determined by cytometric bead technology. One-way ANOVA with Newman-Keuls post-hoc test was used to analyze statistical significance. 


\section{References}

Ahmed, M., Davis, J., Aucoin, D., Sato, T., Ahuja, S., Aimoto, S., . . Smith, S. O. (2010). Structural conversion of neurotoxic amyloid-beta(1-42) oligomers to fibrils. Nat Struct Mol Biol, 17(5), 561-567. doi:10.1038/nsmb.1799

Akama, K. T., \& McEwen, B. S. (2003). Estrogen stimulates postsynaptic density-95 rapid protein synthesis via the Akt/protein kinase B pathway. J Neurosci, 23(6), 2333-2339.

Akiyama, H., Barger, S., Barnum, S., Bradt, B., Bauer, J., Cole, G. M., . . Wyss-Coray, T. (2000). Inflammation and Alzheimer's disease. Neurobiol Aging, 21(3), 383-421.

Asselineau, D., Benlhassan, K., Arosio, B., Mari, D., Ferri, E., Casati, M., . . Bray, D. H. (2015). Interleukin-10 Production in Response to Amyloid-beta Differs between Slow and Fast Decliners in Patients with Alzheimer's Disease. J Alzheimers Dis, 46(4), 837-842. doi:10.3233/JAD-142832

Bilousova, T., Miller, C. A., Poon, W. W., Vinters, H. V., Corrada, M., Kawas, C., . . Gylys, K. H. (2016). Synaptic Amyloid-beta Oligomers Precede p-Tau and Differentiate High Pathology Control Cases. Am J Pathol, 186(1), 185-198. doi:10.1016/j.ajpath.2015.09.018

Burdick, D., Soreghan, B., Kwon, M., Kosmoski, J., Knauer, M., Henschen, A., . . Glabe, C. (1992). Assembly and aggregation properties of synthetic Alzheimer's A4/beta amyloid peptide analogs. J Biol Chem, 267(1), 546-554.

Bustin, S. A., Benes, V., Garson, J. A., Hellemans, J., Huggett, J., Kubista, M., . . Wittwer, C. T. (2009). The MIQE guidelines: minimum information for publication of quantitative real-time PCR experiments. Clin Chem, 55(4), 611-622. doi:10.1373/clinchem.2008.112797

Cattaneo, A., Cattane, N., Galluzzi, S., Provasi, S., Lopizzo, N., Festari, C., . . . Group, I.-F. (2017). Association of brain amyloidosis with pro-inflammatory gut bacterial taxa and peripheral inflammation markers in cognitively impaired elderly. Neurobiol Aging, 49, 60-68. doi:10.1016/j.neurobiolaging.2016.08.019

Coll, R. C., Robertson, A. A., Chae, J. J., Higgins, S. C., Munoz-Planillo, R., Inserra, M. C., . . O'Neill, L. A. (2015). A small-molecule inhibitor of the NLRP3 inflammasome for the treatment of inflammatory diseases. Nat Med, 21(3), 248-255. doi:10.1038/nm.3806

Daniels, M. J., Rivers-Auty, J., Schilling, T., Spencer, N. G., Watremez, W., Fasolino, V., . . Brough, D. (2016). Fenamate NSAIDs inhibit the NLRP3 inflammasome and protect against Alzheimer's disease in rodent models. Nat Commun, 7, 12504. doi:10.1038/ncomms12504

Dempsey, C., Rubio Araiz, A., Bryson, K. J., Finucane, O., Larkin, C., Mills, E. L., . . Lynch, M. A. (2016). Inhibiting the NLRP3 inflammasome with MCC950 promotes non-phlogistic clearance of amyloid-beta and cognitive function in APP/PS1 mice. Brain Behav Immun. doi:10.1016/j.bbi.2016.12.014

Denes, A., Coutts, G., Lenart, N., Cruickshank, S. M., Pelegrin, P., Skinner, J., . . Brough, D. (2015). AIM2 and NLRC4 inflammasomes contribute with ASC to acute brain injury independently of NLRP3. Proc Natl Acad Sci U S A, 112(13), 4050-4055. doi:10.1073/pnas.1419090112

Eikelenboom, P., \& Stam, F. C. (1982). Immunoglobulins and complement factors in senile plaques. An immunoperoxidase study. Acta Neuropathol, 57(2-3), 239-242.

El Khoury, J., Hickman, S. E., Thomas, C. A., Cao, L., Silverstein, S. C., \& Loike, J. D. (1996). Scavenger receptor-mediated adhesion of microglia to beta-amyloid fibrils. Nature, 382(6593), 716-719. doi:10.1038/382716a0

Forny-Germano, L., Lyra e Silva, N. M., Batista, A. F., Brito-Moreira, J., Gralle, M., Boehnke, S. E., . . . De Felice, F. G. (2014). Alzheimer's disease-like pathology induced by amyloid-beta oligomers in nonhuman primates. J Neurosci, 34(41), 13629-13643. doi:10.1523/JNEUROSCI.1353-14.2014

Frautschy, S. A., Hu, W., Kim, P., Miller, S. A., Chu, T., Harris-White, M. E., \& Cole, G. M. (2001). Phenolic anti-inflammatory antioxidant reversal of Abeta-induced cognitive deficits and neuropathology. Neurobiol Aging, 22(6), 993-1005. 
Frautschy, S. A., Yang, F., Calderon, L., \& Cole, G. M. (1996). Rodent models of Alzheimer's disease: rat A beta infusion approaches to amyloid deposits. Neurobiol Aging, 17(2), 311-321.

Garcia-Matas, S., de Vera, N., Aznar, A. O., Marimon, J. M., Adell, A., Planas, A. M., . . Sanfeliu, C. (2010). In vitro and in vivo activation of astrocytes by amyloid-beta is potentiated by prooxidant agents. J Alzheimers Dis, 20(1), 229-245. doi:10.3233/JAD-2010-1365

Griffin, W. S., Stanley, L. C., Ling, C., White, L., MacLeod, V., Perrot, L. J., . . Araoz, C. (1989). Brain interleukin 1 and S-100 immunoreactivity are elevated in Down syndrome and Alzheimer disease. Proc Natl Acad Sci U S A, 86(19), 7611-7615.

Halle, A., Hornung, V., Petzold, G. C., Stewart, C. R., Monks, B. G., Reinheckel, T., . . Golenbock, D. T. (2008). The NALP3 inflammasome is involved in the innate immune response to amyloid-beta. Nat Immunol, 9(8), 857-865. doi:10.1038/ni.1636

Halverson, K., Fraser, P. E., Kirschner, D. A., \& Lansbury, P. T., Jr. (1990). Molecular determinants of amyloid deposition in Alzheimer's disease: conformational studies of synthetic beta-protein fragments. Biochemistry, 29(11), 2639-2644.

Hanisch, U. K., \& Kettenmann, H. (2007). Microglia: active sensor and versatile effector cells in the normal and pathologic brain. Nat Neurosci, 10(11), 1387-1394. doi:10.1038/nn1997

Hart, S. A., Snyder, M. A., Smejkalova, T., \& Woolley, C. S. (2007). Estrogen mobilizes a subset of estrogen receptor-alpha-immunoreactive vesicles in inhibitory presynaptic boutons in hippocampal CA1. J Neurosci, 27(8), 2102-2111. doi:10.1523/JNEUROSCI.5436-06.2007

He, Y., Zheng, M. M., Ma, Y., Han, X. J., Ma, X. Q., Qu, C. Q., \& Du, Y. F. (2012). Soluble oligomers and fibrillar species of amyloid beta-peptide differentially affect cognitive functions and hippocampal inflammatory response. Biochem Biophys Res Commun, 429(3-4), 125-130. doi:10.1016/j.bbrc.2012.10.129

Heneka, M. T., Carson, M. J., El Khoury, J., Landreth, G. E., Brosseron, F., Feinstein, D. L., . . Kummer, M. P. (2015). Neuroinflammation in Alzheimer's disease. Lancet Neurol, 14(4), 388-405. doi:10.1016/S1474-4422(15)70016-5

Heneka, M. T., Kummer, M. P., Stutz, A., Delekate, A., Schwartz, S., Vieira-Saecker, A., . . Golenbock, D. T. (2013). NLRP3 is activated in Alzheimer's disease and contributes to pathology in APP/PS1 mice. Nature, 493(7434), 674-678. doi:10.1038/nature11729

Hojo, Y., Hattori, T. A., Enami, T., Furukawa, A., Suzuki, K., Ishii, H. T., ... Kawato, S. (2004). Adult male rat hippocampus synthesizes estradiol from pregnenolone by cytochromes P45017alpha and P450 aromatase localized in neurons. Proc Natl Acad Sci U S A, 101(3), 865-870. doi:10.1073/pnas.2630225100

Hong, S., Beja-Glasser, V. F., Nfonoyim, B. M., Frouin, A., Li, S., Ramakrishnan, S., . . Stevens, B. (2016). Complement and microglia mediate early synapse loss in Alzheimer mouse models. Science, 352(6286), 712-716. doi:10.1126/science.aad8373

Hu, X. Y., Qin, S., Lu, Y. P., Ravid, R., Swaab, D. F., \& Zhou, J. N. (2003). Decreased estrogen receptoralpha expression in hippocampal neurons in relation to hyperphosphorylated tau in Alzheimer patients. Acta Neuropathol, 106(3), 213-220. doi:10.1007/s00401-003-0720-3

Ishunina, T. A., Fischer, D. F., \& Swaab, D. F. (2007). Estrogen receptor alpha and its splice variants in the hippocampus in aging and Alzheimer's disease. Neurobiol Aging, 28(11), 1670-1681. doi:10.1016/j.neurobiolaging.2006.07.024

Itagaki, S., McGeer, P. L., Akiyama, H., Zhu, S., \& Selkoe, D. (1989). Relationship of microglia and astrocytes to amyloid deposits of Alzheimer disease. J Neuroimmunol, 24(3), 173-182.

Kadish, I., Thibault, O., Blalock, E. M., Chen, K. C., Gant, J. C., Porter, N. M., \& Landfield, P. W. (2009). Hippocampal and cognitive aging across the lifespan: a bioenergetic shift precedes and increased cholesterol trafficking parallels memory impairment. J Neurosci, 29(6), 1805-1816. doi:10.1523/JNEUROSCI.4599-08.2009

Kirschner, D. A., Inouye, H., Duffy, L. K., Sinclair, A., Lind, M., \& Selkoe, D. J. (1987). Synthetic peptide homologous to beta protein from Alzheimer disease forms amyloid-like fibrils in vitro. Proc Natl Acad Sci U S A, 84(19), 6953-6957. 
Kuo, Y. M., Emmerling, M. R., Vigo-Pelfrey, C., Kasunic, T. C., Kirkpatrick, J. B., Murdoch, G. H., ... Roher, A. E. (1996). Water-soluble Abeta (N-40, N-42) oligomers in normal and Alzheimer disease brains. J Biol Chem, 271(8), 4077-4081.

Lecanu, L., Greeson, J., \& Papadopoulos, V. (2006). Beta-amyloid and oxidative stress jointly induce neuronal death, amyloid deposits, gliosis, and memory impairment in the rat brain. Pharmacology, 76(1), 19-33. doi:10.1159/000088929

Lesne, S., Koh, M. T., Kotilinek, L., Kayed, R., Glabe, C. G., Yang, A., . . Ashe, K. H. (2006). A specific amyloid-beta protein assembly in the brain impairs memory. Nature, 440(7082), 352-357. doi:10.1038/nature04533

Li, X., Long, J., He, T., Belshaw, R., \& Scott, J. (2015). Integrated genomic approaches identify major pathways and upstream regulators in late onset Alzheimer's disease. Sci Rep, 5, 12393. doi:10.1038/srep12393

Louveau, A., Nerriere-Daguin, V., Vanhove, B., Naveilhan, P., Neunlist, M., Nicot, A., \& Boudin, H. (2015). Targeting the CD80/CD86 costimulatory pathway with CTLA4-Ig directs microglia toward a repair phenotype and promotes axonal outgrowth. Glia, 63(12), 2298-2312. doi:10.1002/glia.22894

Lucin, K. M., \& Wyss-Coray, T. (2009). Immune activation in brain aging and neurodegeneration: too much or too little? Neuron, 64(1), 110-122. doi:10.1016/j.neuron.2009.08.039

Lue, L. F., Kuo, Y. M., Roher, A. E., Brachova, L., Shen, Y., Sue, L., . . Rogers, J. (1999). Soluble amyloid beta peptide concentration as a predictor of synaptic change in Alzheimer's disease. Am J Pathol, 155(3), 853-862.

Maezawa, I., Zimin, P. I., Wulff, H., \& Jin, L. W. (2011). Amyloid-beta protein oligomer at low nanomolar concentrations activates microglia and induces microglial neurotoxicity. J Biol Chem, 286(5), 3693-3706. doi:10.1074/jbc.M110.135244

McEwen, B., Akama, K., Alves, S., Brake, W. G., Bulloch, K., Lee, S., ... Milner, T. A. (2001). Tracking the estrogen receptor in neurons: implications for estrogen-induced synapse formation. Proc Natl Acad Sci U S A, 98(13), 7093-7100. doi:10.1073/pnas.121146898

McEwen, B. S., Akama, K. T., Spencer-Segal, J. L., Milner, T. A., \& Waters, E. M. (2012). Estrogen effects on the brain: actions beyond the hypothalamus via novel mechanisms. Behav Neurosci, 126(1), 4-16. doi:10.1037/a0026708

McGeer, P. L., Itagaki, S., Tago, H., \& McGeer, E. G. (1987). Reactive microglia in patients with senile dementia of the Alzheimer type are positive for the histocompatibility glycoprotein HLA-DR. Neurosci Lett, 79(1-2), 195-200.

Muller-Schiffmann, A., Herring, A., Abdel-Hafiz, L., Chepkova, A. N., Schable, S., Wedel, D., . . Korth, C. (2016). Amyloid-beta dimers in the absence of plaque pathology impair learning and synaptic plasticity. Brain, 139(Pt 2), 509-525. doi:10.1093/brain/awv355

Muruve, D. A., Petrilli, V., Zaiss, A. K., White, L. R., Clark, S. A., Ross, P. J., . . Tschopp, J. (2008). The inflammasome recognizes cytosolic microbial and host DNA and triggers an innate immune response. Nature, 452(7183), 103-107. doi:10.1038/nature06664

Nilsson, P., Saito, T., \& Saido, T. C. (2014). New mouse model of Alzheimer's. ACS Chem Neurosci, 5(7), 499-502. doi:10.1021/cn500105p

Nimmerjahn, A., Kirchhoff, F., \& Helmchen, F. (2005). Resting microglial cells are highly dynamic surveillants of brain parenchyma in vivo. Science, 308(5726), 1314-1318. doi:10.1126/science.1110647

Rathinam, V. A., \& Fitzgerald, K. A. (2016). Inflammasome Complexes: Emerging Mechanisms and Effector Functions. Cell, 165(4), 792-800. doi:10.1016/j.cell.2016.03.046

Reed-Geaghan, E. G., Savage, J. C., Hise, A. G., \& Landreth, G. E. (2009). CD14 and toll-like receptors 2 and 4 are required for fibrillar A\{beta\}-stimulated microglial activation. $J$ Neurosci, 29(38), 11982-11992. doi:10.1523/JNEUROSCI.3158-09.2009

Remarque, E. J., Bollen, E. L., Weverling-Rijnsburger, A. W., Laterveer, J. C., Blauw, G. J., \& Westendorp, R. G. (2001). Patients with Alzheimer's disease display a pro-inflammatory phenotype. Exp Gerontol, 36(1), 171-176. 
Ryan, T. M., Caine, J., Mertens, H. D., Kirby, N., Nigro, J., Breheney, K., . . Roberts, B. R. (2013). Ammonium hydroxide treatment of Abeta produces an aggregate free solution suitable for biophysical and cell culture characterization. PeerJ, 1, e73. doi:10.7717/peerj.73

Sarvari, M., Kallo, I., Hrabovszky, E., Solymosi, N., \& Liposits, Z. (2014). Ovariectomy and subsequent treatment with estrogen receptor agonists tune the innate immune system of the hippocampus in middle-aged female rats. PLoS One, 9(2), e88540. doi:10.1371/journal.pone.0088540

Shankar, G. M., Li, S., Mehta, T. H., Garcia-Munoz, A., Shepardson, N. E., Smith, I., . . Selkoe, D. J. (2008). Amyloid-beta protein dimers isolated directly from Alzheimer's brains impair synaptic plasticity and memory. Nat Med, 14(8), 837-842. doi:10.1038/nm1782

Shughrue, P. J., \& Merchenthaler, I. (2000). Evidence for novel estrogen binding sites in the rat hippocampus. Neuroscience, 99(4), 605-612.

Swardfager, W., Lanctot, K., Rothenburg, L., Wong, A., Cappell, J., \& Herrmann, N. (2010). A metaanalysis of cytokines in Alzheimer's disease. Biol Psychiatry, 68(10), 930-941. doi:10.1016/j.biopsych.2010.06.012

Tian, L., Rauvala, H., \& Gahmberg, C. G. (2009). Neuronal regulation of immune responses in the central nervous system. Trends Immunol, 30(2), 91-99. doi:10.1016/j.it.2008.11.002

Vegeto, E., Belcredito, S., Etteri, S., Ghisletti, S., Brusadelli, A., Meda, C., ... Maggi, A. (2003). Estrogen receptor-alpha mediates the brain antiinflammatory activity of estradiol. Proc Natl Acad Sci U $S$ A, 100(16), 9614-9619. doi:10.1073/pnas.1531957100

Verret, L., Mann, E. O., Hang, G. B., Barth, A. M., Cobos, I., Ho, K., . . Palop, J. J. (2012). Inhibitory interneuron deficit links altered network activity and cognitive dysfunction in Alzheimer model. Cell, 149(3), 708-721. doi:10.1016/j.cell.2012.02.046

Vorhees, C. V., \& Williams, M. T. (2006). Morris water maze: procedures for assessing spatial and related forms of learning and memory. Nat Protoc, 1(2), 848-858. doi:10.1038/nprot.2006.116

Wang, Z., Jackson, R. J., Hong, W., Taylor, W. M., Corbett, G. T., Moreno, A., . . Walsh, D. M. (2017). Human Brain-Derived Abeta Oligomers Bind to Synapses and Disrupt Synaptic Activity in a Manner That Requires APP. J Neurosci, 37(49), 11947-11966. doi:10.1523/JNEUROSCI.200917.2017

Yasojima, K., Schwab, C., McGeer, E. G., \& McGeer, P. L. (1999). Up-regulated production and activation of the complement system in Alzheimer's disease brain. Am J Pathol, 154(3), 927-936. doi:10.1016/S0002-9440(10)65340-0

Zanjani, H., Finch, C. E., Kemper, C., Atkinson, J., McKeel, D., Morris, J. C., \& Price, J. L. (2005). Complement activation in very early Alzheimer disease. Alzheimer Dis Assoc Disord, 19(2), 5566. 